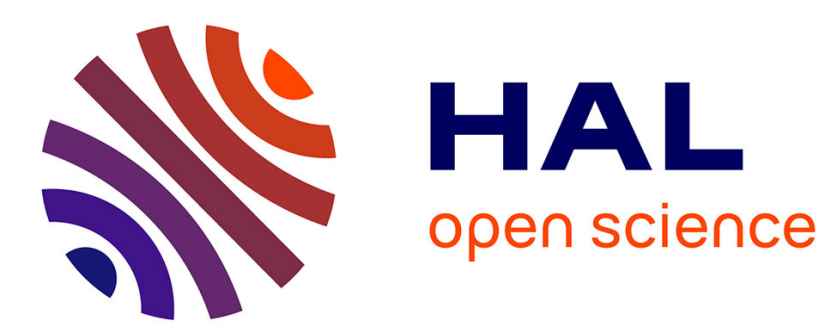

\title{
Additive manufacturing of magnetic materials using selective laser melting
}

\author{
Baydaa Obeid, David Pietroy, Bernard Bayard, Jean-Pierre Chatelon, \\ Stéphane Capraro, Jean-Jacques J Rousseau
}

\section{To cite this version:}

Baydaa Obeid, David Pietroy, Bernard Bayard, Jean-Pierre Chatelon, Stéphane Capraro, et al.. Additive manufacturing of magnetic materials using selective laser melting. 3D Printed Optics and Additive Photonic Manufacturing II, Apr 2020, Online Only, France. pp.31, 10.1117/12.2560163 . hal-02547688

\section{HAL Id: hal-02547688 \\ https://hal.science/hal-02547688}

Submitted on 20 Apr 2020

HAL is a multi-disciplinary open access archive for the deposit and dissemination of scientific research documents, whether they are published or not. The documents may come from teaching and research institutions in France or abroad, or from public or private research centers.
L'archive ouverte pluridisciplinaire HAL, est destinée au dépôt et à la diffusion de documents scientifiques de niveau recherche, publiés ou non, émanant des établissements d'enseignement et de recherche français ou étrangers, des laboratoires publics ou privés. 


\section{Additive manufacturing of magnetic materials using selective laser melting}

Obeid, B., Piétroy, D., Bayard, B., Chatelon, J. P., Capraro, S., et al.

B. Obeid, D. Piétroy, B. Bayard, J. P. Chatelon, S. Capraro, J. J. Rousseau, "Additive manufacturing of magnetic materials using selective laser melting," Proc. SPIE 11349, 3D Printed Optics and Additive Photonic Manufacturing II, 113490T (13 April 2020); doi: 10.1117/12.2560163

SPIE. Event: SPIE Photonics Europe, 2020, Online Only, France 


\title{
Additive manufacturing of magnetic materials using selective laser melting
}

\author{
B. Obeid, ${ }^{\text {a } D . ~ P i e ́ t r o y * a, ~ B . ~ B a y a r d ~}{ }^{\text {a }}$, J. P. Chatelon ${ }^{\mathrm{a}}$, S. Capraro ${ }^{\mathrm{a}}$, J. J. Rousseau ${ }^{\mathrm{a}}$ \\ ${ }^{a}$ Univ. Lyon, Laboratoire Hubert Curien UMR 5516 CNRS, Université Jean Monnet, F-42000 Saint- \\ Étienne, France.
}

\begin{abstract}
Magnetic material is the key component in lot of electromagnetically-based optical to microwave applications. In the case of radio-frequencies/microwave applications, passive components are developed using planar design to facilitate their fabrication while 3D geometries are the best shapes to improve components properties. But nowadays, 3D printing technologies are coming up in industries and 3D design of passive components grows in interest. But 3D shaping of magnetic material remains a problem which has to be solved before considering industrial implementation.

In this work, we demonstrate the possibility of 3D shaping ferrite magnetic powder using Selective laser melting/sintering in ambient air. A ferrimagnetic powder of Yttrium Iron Garnet (YIG) was used to form a 10-layers stack of magnetic material. A simple method for small surface $\left(10 \times 10 \mathrm{~mm}^{2}\right)$ deposition of powder was developed by dispersing the YIG powder into ethanol. A drop is then deposited on top of a substrate. Ethanol evaporates and an homogeneous layer is obtained. A $1064 \mathrm{~nm}$-nanosecond laser combined to a scanning lens is used to irradiate the powder layer and induce melting/sintering of the powder at ambient temperature and in ambient air. Chemical and structural changes induced by the laser process were studied using Raman spectroscopy. Results show that a part of the YIG was decomposed into a weakly magnetic phase of $\mathrm{Fe}_{3} \mathrm{O}_{4}$. Vibrating Sample Magnetometry was then used to compare the magnetic behavior of the YIG multilayer and the YIG powder. The multilayer always exhibit a magnetic behavior whatever the substrate is: YIG powder, YIG bulk or Al bulk.
\end{abstract}

Keywords: magnetic material, YIG, selective laser melting, microwave, radio-frequencies, passive components

\section{INTRODUCTION}

Magnetic materials are key materials in electromagnetically-based applications. In the optical range, they enable Kerr and Faraday effects to manage the polarization state (optical isolators). In the microwave range (MW), they enable nonreciprocal effects to guide the incoming signal (isolators, circulators (fig.1a), etc.). Finally, in the radio-frequency range (RF), they permit to channel and concentrate magnetic field lines to improve electric properties of components and more specifically integrated ones (inductors (fig. 1c), transformers (fig. 1d), converters, etc.). In the case of power electronics or microwave applications, integrated components were planarized to facilitate their fabrication using standard processes of microelectronics industry. But such 2D-designs limit their performances and achievable functions. On the other hand, the design of 3D-shaped toroid coils (fig. 1b) will reduce the losses and electromagnetic radiation of an inductor or transformer. ${ }^{1}$ 3D design of ferrite circulators can be used to increase the bandwidth by stacking two circulators with different working frequencies with their polarization coils and permanent magnets. ${ }^{2} 3 \mathrm{D}$ printing method also allows convenient fabrication of metamaterials. ${ }^{3}$ However, integration of $3 \mathrm{D}$ magnetic components is challenging due to unconventional geometries to distribute flux or control coupling.

Usually, magnetic materials are shaped as a bulk material which also acts as a mechanical holder. Standard sintering process at high temperature and pressure are then used to give the magnetic powder a 3D-shape. ${ }^{4}$ Such manufacturing process leads to very low resolution. However, in most applications, a small and localized volume (MW and optical applications) or a specific 3D-shape of the magnetic material is required to decrease energy losses or to improve components properties. Therefore, there is a need in $\mathrm{RF}^{5-8}$ and $\mathrm{MW}^{9-10}$ applications for additive manufacturing technology that can meet following objectives: reduced production times, flexibility in the design of 3D components, simplification of manufacturing steps, reduction of the size and weight of the components and performance increase.

*david.pietroy@univ-st-etienne.fr; phone +33 477915 815; fax +33 477915880

3D Printed Optics and Additive Photonic Manufacturing II, edited by Alois M. Herkommer, Georg von Freymann, Manuel Flury, Proc. of SPIE Vol. 11349, 113490T · (c) 2020 SPIE · CCC code: 0277-786X/20/\$21 · doi: 10.1117/12.2560163 
$3 \mathrm{D}$ printing of magnetic components is already studied in power electronics ${ }^{11-12}$. Nowadays, the most promising technique to reach this $3 \mathrm{D}$ shaping deals with a composite approach in which the magnetic powder is mixed with a polymer. ${ }^{13}$ A standard FDM 3D printing technique is then used to fabricate 3D magnetic components, but such a technique leads to a poor magnetic material density. To increase it, it is necessary to add complex steps of debinding and sintering to obtain a fully densified magnetic structure.

Thus, a direct additive manufacturing process of magnetic material is of high interest for several applications based on magnetic materials. But such a process should not induce too many chemical or structural modifications which could induce modifications in the magnetic properties of the material. Laser technologies such as laser engineered net shape (LENS) and selective laser melting (SLM) were already used to perform additive manufacturing for some magnetic materials. White et al. applied LENS to print permanent magnets of AlNiCo. Results showed a small decrease in remanence and an intrinsic coercivity equivalent to the initial material. ${ }^{14}$ Additive manufacturing of soft magnetic materials based on Fe alloys was also demonstrated using both LENS and SLM. ${ }^{15-19}$ It was pointed out that chemical and structural changes occur. A strong increase in the intrinsic coercivity due to laser processes was also observed. In another range of application, the additive manufacturing of magnetocaloric materials was also achieved using selective laser sintering (SLS). ${ }^{20}$

In this work, we propose to study the possibility of using selective laser melting (SLM) to 3D-shape a commercial magnetic ferrite powder dedicated to RF and MW applications. Yttrium Iron Garnet (YIG) is chosen because of its wide use in both RF and MW applications. To reach this goal, a simple deposition method of powder layer was developed and the SLM parameters quickly optimized. Layers obtained after SLM are magnetically characterized using Vibrating Sample Magnetometry (VSM) and chemical and structural modifications investigated using Raman spectroscopy.

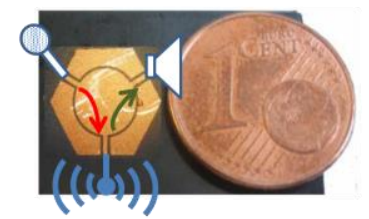

a) Planar integrated circulator

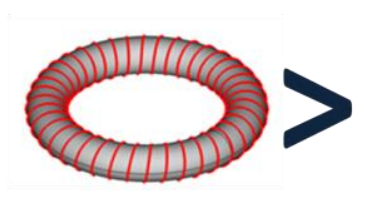

b) $3 D$ toroid inductor

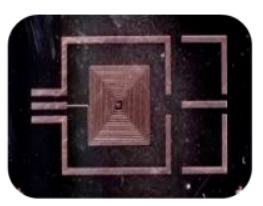

c) 20 planarinductor

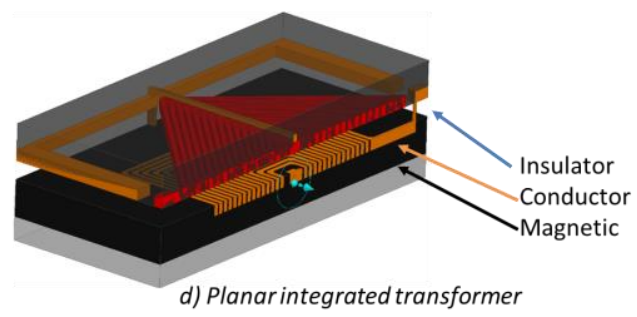

Figure 1. (a) Image of a planar integrated circulator which allows the incoming signal from the antenna to be routed to the speaker and the signal from the microphone e to be routed to the antenna. (b) scheme of a toroid inductor. (c) image of an integrated inductor.

\section{SELECTIVE LASER MELTING}

A laser-induced thermal process for additive manufacturing can involve different binding processes. ${ }^{21}$ In the case of laser melting, laser energy is absorbed by the powder then turned into a heat source which permits to increase the material temperature till the melting of the material. Heating and phase transformation also induce a fluid flow during such processes making their multi-physics modelling very complex. Several technics based on laser melting were developed to achieve 3D printing. Some technics project the powder molten by a high power laser on top of the substrate ${ }^{22-23}$ while, in the case of selective laser melting, the powder layer is deposited on top of the substrate then it is melted using the high power laser. ${ }^{24-25}$

SLM machines are now available in most industries (automotive, avionics, aerospace, etc.) and for a wide range of materials (metals, ceramics, composites, etc.). ${ }^{24}$ A SLM process is actually composed of two main steps: powder deposition and laser melting. Each one is critical to the success of the manufacture of the final object and they strongly depends on both powder properties and laser parameters. SLM is a thermal process which is obviously driven by material and laser properties, but also by the powder properties. Concerning the material properties, optical absorption at 
laser wavelength and thermal conductivity will be of utmost importance. Concerning laser parameters, laser power and wavelength will be very important but the waist of the focused beam, and the scanning speed and strategy will also have a strong influence on the result. ${ }^{26-27}$ Finally, grain size distribution and shape and layer thickness will also modify effective thermal conductivity and absorption of the powder material and therefore modify the laser-matter interaction. Thus, to get the best result using a SLM process, it is necessary to get the most homogeneous grain size and shape for the powder, to deposit an homogenous layer thickness of powder, then to optimize laser power and scanning speed and strategy.

Powder layer deposition is a critical step since the thickness has to be quite homogeneous on the overall surface. A change in thickness could induce a change in heat transfer then in material melting. Available SLM machines are commonly based on a powder bed system. ${ }^{28}$ The classical setup deals with connected vessels. The first one provides the powder while the second receives the powder to be melted. The substrate is usually deposited in this second vessel, on top of a vertical translation stage which permits to adjust the powder layer thickness and also to stack several melted layers. Finally, a scraping or rolling tool homogeneously spreads the powder before laser melting. Such a setup is very efficient but is quite complex to develop.

Laser used in selective laser melting strongly depends on the material to process. As a thermal effect is wanted, CWlasers are the best candidates but nanosecond pulsed lasers are also suitable. The material determines the laser wavelength as the highest optical absorption is needed to convert laser energy into heat energy. Standard lasers used in SLM are $\mathrm{CO}_{2}(10.6 \mu \mathrm{m})$ and YAG $(1064 \mathrm{~nm})$. As the material has to be melted, high power lasers are required (several tens of watts).

The last important element is the optical scanning system and mainly the focal length of the F-theta lens. The focused beam diameter will define the interaction area thus the energy density on top of the substrate. It will drive the local temperature of the material with the laser power, scanning speed and optical and thermal properties of the material.

\section{EXPERIMENTAL DETAILS}

In this work, as we only aim at demonstrating the possibility of using SLM process to 3D shape magnetic material, we focused on developing trivial setups to achieve the manufacture of a maximum $10 \times 10 \mathrm{~mm}^{2}$ layer with a few hundred microns thickness. Such dimensions are more than enough to make a large number of components.

\subsection{Powder deposition}

Two trivial setups were tested to deposit a homogeneous powder layer. In a first setup, a specific aluminum holder is mechanically machined to receive a $635 \mu \mathrm{m}$ alumina plate. The machining is adjusted so that the top surface of the alumina substrate was about $50 \mu \mathrm{m}$ from the top surface of the holder top. Powder is added on top of the alumina substrate then spread using a microscope slide to ensure flat powder surface therefore to ensure homogeneous thickness of the powder layer. Such a method provides a good repeatability on a few $\mathrm{cm}^{2}$ area but is not so easy to use. Moreover, stacking of layers is not possible.

In a second setup, powder is dispersed in ethanol. The solution is quietly mixed to homogenize the solution paying attention to avoid bubbles. Part of the solution is pumped using a micropipette and kept manually mixed. A drop is deposited on top of the surface. The drop naturally spreads on top of the substrate and ethanol evaporates inducing a quite homogeneous powder layer thickness. The homogeneous area is smaller than with the first setup (few tens of $\mathrm{mm}^{2}$ ) but it remains very user-friendly. Another advantage is that powder adheres better to the surface which avoids hazards due to powder dispersion in the ambient air. Finally, this method is very suitable to stack several layers. The homogeneity in the layer thickness was measured using a standard optical microscope with an automatic ztranslation stage. A x63 objective was used to reduce the depth of focus. The z position for a sharp image of the surface is measured in several points of the sample. Tilt of the sample is taken into account by measuring the $\mathrm{z}$ position of the flat substrate top surface in several point around the powdered area. Finally, powder thickness is locally estimated by subtracting the interpolated z-value of the substrate surface to the z-value of the powder surface.

\subsection{Laser Setup}

A laser marking workbench from technifor (lasertop 2000) was used. The embedded laser is a YAG pulsed laser with a $10 \mathrm{~ns}$ pulse duration, a $200 \mathrm{kHz}$ repetition rate and a $12 \mathrm{~W}$ maximum accordable power. The $1064 \mathrm{~nm}$ wavelength is 
relatively well absorbed by the YIG. An advantage of such a commercial machine is that the optical system and software are already integrated, making it easy to design and mark complex planar geometries with different scan strategies.

The lens is a $160 \mathrm{~mm}$ F-theta lens giving a $40 \mu \mathrm{m}$ focused laser beam on top of the substrate. The complete laser system permits to reach a maximal average power density about $1 \mathrm{MW} / \mathrm{cm}^{2}$ for a maximal energy density of $5 \mathrm{~J} / \mathrm{cm}^{2}$.

\subsection{Selective laser melting process for YIG powder}

In this work, we focused on a commercial YIG powder from Neyco company. Grain size distribution is not known but grain size was estimated to be about $10 \mu \mathrm{m}$ using optical microscopy. Thermal conductivity of bulk material is quite low $35 \mathrm{~W} / \mathrm{m} . \mathrm{K}$ which should limit heat diffusion then promote local temperature increase. As explained in Fig. 2, the process is following four main steps:

1- a YIG-ethanol solution was prepared with a concentration of $400 \mathrm{~g} / \mathrm{L}$ by mixing $1.2 \mathrm{~g}$ of $\mathrm{YIG}$ powder in $3 \mathrm{~mL}$ of ethanol.

2- Solution was deposited on top of the substrate to form a 40-50 $\mu$ m layer of powder.

3- The powder layer was then irradiated at $200 \mathrm{kHz}$ and using a standard line-by-line scanning strategy

4- Steps 2 and 3 were repeated according to the number of layers desired

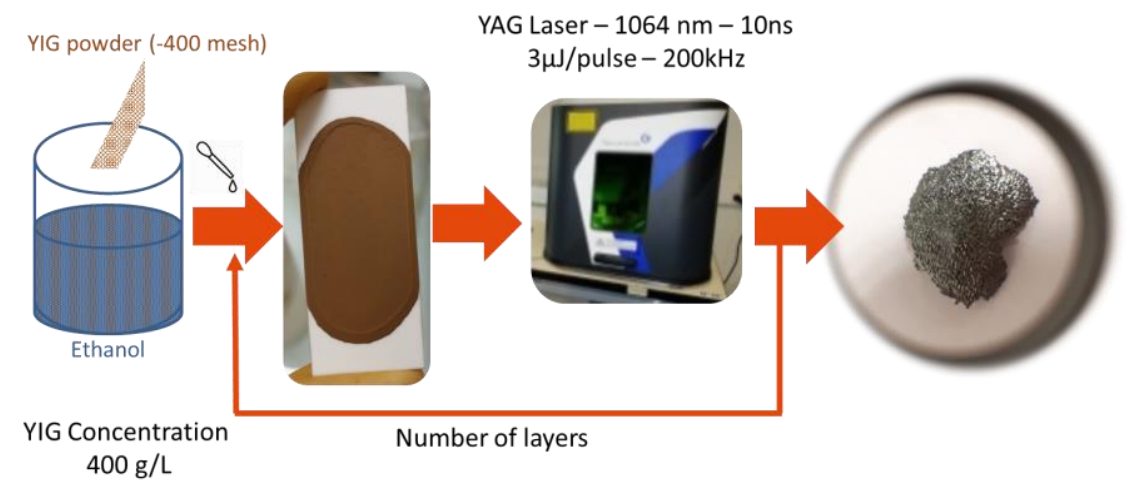

Figure 2. Scheme of the selective laser melting process used to process YIG powder.

The process was tested by depositing a single layer on different substrates (aluminum, alumina, glass, bulk and powder YIG). For each substrate, both laser and scanning speed were optimized to get the best visual result. But we focused on two specific cases: bulk aluminum substrate and directly in YIG powder bed for more physical investigations concerning magnetism and material modifications with the idea of easily unsticking the layer from the substrate. Three main samples were fabricated:

- Sample A is a $10 \times 10 \mathrm{~mm}^{2}$ multilayer of 10 SLM layers fabricated on top of a non-magnetic aluminum substrate. The final thickness is $380 \mu \mathrm{m}$. The SLM layers were obtained using a laser at $0.6 \mathrm{~W}$ power $(3 \mu \mathrm{J} / \mathrm{pulse})$ and $200 \mathrm{kHz}$ repetition rate. The scanning speed was $50 \mathrm{~mm} / \mathrm{s}$.

- Sample B is a $10 x 10 \mathrm{~mm}^{2}$ multilayer of 10 SLM layers directly fabricated in the magnetic YIG powder bed. The final thickness is $270 \mu \mathrm{m}$. The SLM layers were obtained using a laser at $1.8 \mathrm{~W}$ power $(9 \mu \mathrm{J} / \mathrm{pulse})$ and $200 \mathrm{kHz}$ repetition rate. The scanning speed was $50 \mathrm{~mm} / \mathrm{s}$.

- Sample C is a $2 \times 2 \mathrm{~mm}^{2}$ multilayer of 10 SLM layers directly fabricated in the magnetic YIG powder bed. The final thickness is $200 \mu \mathrm{m}$. The SLM layers were obtained using a laser at $12 \mathrm{~W}$ power $(60 \mu \mathrm{J} / \mathrm{pulse})$ and $200 \mathrm{kHz}$ repetition rate. The scanning speed was $150 \mathrm{~mm} / \mathrm{s}$.

After unsticking from the substrate, samples were cleaned in an ethanol ultrasound bath to remove residual powder. Prior to this cleaning, the rear face (powder/SLM-layer) of samples B and C was also irradiated to melt the residual powder. As both magnetic and Raman analyzers require small objects, a small part (few $\mathrm{mm}^{2}$ ) of each SLM-layer was cut then weighed using a high-precision scale. Assuming the SLM process does not modify the chemical composition of the 
material, sample volume was calculated from the measured mass and using the theoretical YIG density $\left(5.11 \mathrm{~g} / \mathrm{cm}^{3}\right)$. This method has the advantage of not taking into account the porosity of the material induced by the process.

\section{RESULTS AND DISCUSSION}

A first comparison deals with the effect of process parameters. For samples A and B, laser power was adjusted to work close to the melting temperature of the YIG powder. The difference in substrates between sample A and sample B should provide two kinds of information concerning the influence of magnetic properties and thermal conductivity of the substrate on magnetic properties of the layer. Samples B and C were fabricated on top of the same substrate but with different laser power. Comparing the two samples should permit to highlight the influence of melting temperature on material chemical and structural changes.

A first observation can be made concerning the thickness of the sample. The thickness of sample A was $380 \mu \mathrm{m}$ which is about equal to the product of the powder layer thickness by the number of layers deposited. The thicknesses of sample B and $\mathrm{C}$ are respectively equal to $280 \mu \mathrm{m}$ and $200 \mu \mathrm{m}$ which is far from the theoretical value. This could be simply explained by the fact that the pulsed laser induces a shock wave which sweeps away part of the powder then reduces the multilayer thickness.

Sections 4.1 and 4.2 will respectively detail the magnetic and Raman analysis of these three samples and compare them with the initial properties of the YIG powder.

\subsection{Magnetic characterization}

Magnetic properties of the YIG powder and material elaborated by SLM are determined by Vibrating Sample Magnetometer (VSM). The magnetic parameters such as coercive force, saturation magnetization and remanent magnetization were measured with a MPMS SQUID VSM system. This magnetometer system combines the sensitivity of a SQUID (Superconducting Interference Device) with the higher speed of a VSM (Vibrating Sample Magnetometer). The hysteresis loops measured give magnetic moment (in emu) versus magnetic field (in Oersted). The equivalent values in $\mathrm{A} / \mathrm{m}$ were directly converted from Oersted values. However, magnetization values ( $\mu_{0} . \mathrm{M}$ in Tesla) were calculated from the magnetic moment values and from the sample volume.

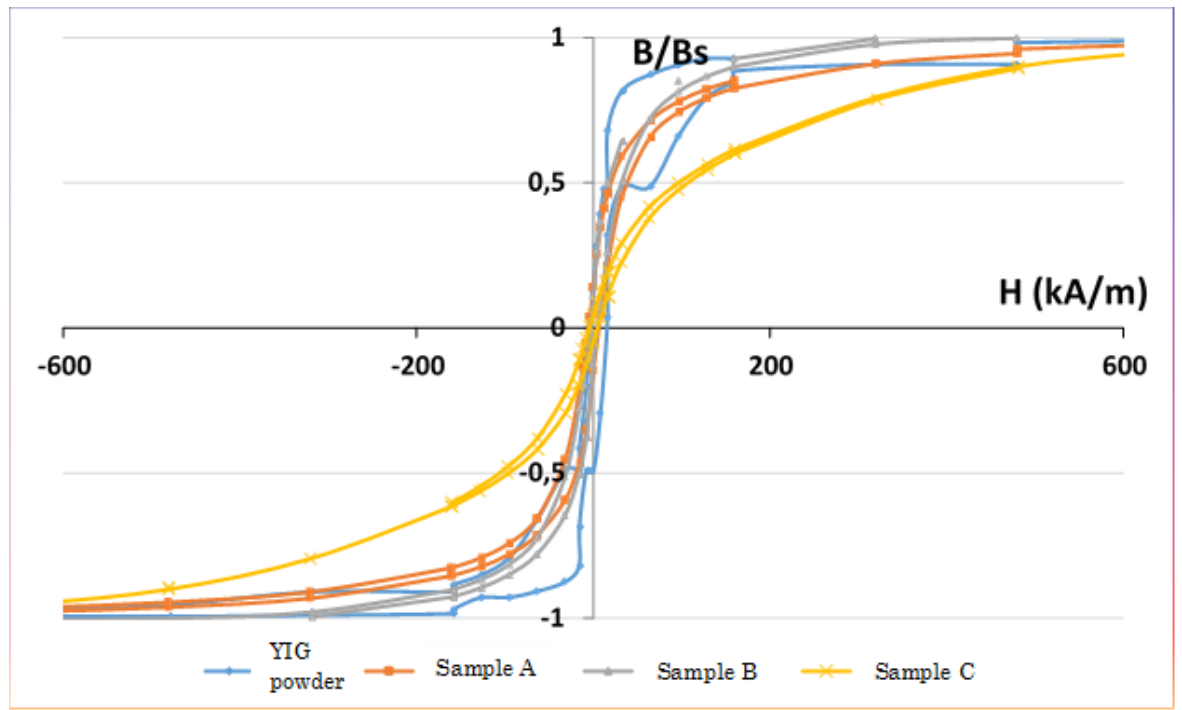

Figure 3. Hysteresis loop for the three SLM layers and for the powder measured using vibrating sample magnetometry.

YIG is a soft magnetic material. Boudiar et al..$^{29}$ found that a minimum temperature of $700^{\circ} \mathrm{C}$ was necessary for the YIG layers to crystallize in the correct phase (FCC), which corresponds to the results reported in the literature. ${ }^{3 .}$ They also noted that a hysteresis loop characteristic of a soft material was obtained only for the crystallized layers. Amorphous YIG does not exhibit a hysteresis loop when analyzed by a VSM. 
Measured hysteresis loop of each sample are given in Fig. 3. To compare hysteresis loop of the samples with the one of the initial YIG powder, results were normalized in magnetic field. For the four samples presented, the hysteresis loop shows a narrow cycle, with a very low coercive field. This is characteristic of soft magnetic materials. So, all SLM samples can therefore be considered as magnetic and the magnetic nature of the substrate does not have any influence on the magnetic properties of the YIG layer fabricated using SLM (comparison of samples A and B).

The hysteresis loop of the powder without SLM treatment is the one with the most vertical slope at the origin: the saturation magnetization is reached faster for the powder than for the three cycles of treated samples. It can be noted that samples A and B presents slope at the origin close to the one of the powder while for sample C, obtained with a higher energy so a higher melting temperature, the cycle is much less square. The difference in slope of the hysteresis loops can be explained by different hypotheses. Firstly, a change in the crystallographic structure of the analyzed material may be at the origin of this difference. The high-energy SLM treatment can change the crystalline phase of the YIG and thus the magnetic behavior is altered. A second hypothesis may be a shape effect. The grains of YIG can thus present a shape anisotropy induced by the SLM treatment. For example, Boudiar et al ${ }^{29}$ have shown that magnetic measurements made with a magnetic field applied in the perpendicular direction or in the plane of a YIG thin film give different hysteresis loops. The saturation magnetization is identical, but the slope at the origin of the loop looks very different. Thus, the magnetic field required to saturate the material is very different in the two cases.

Table 1. Saturation field measured using VSM.

\begin{tabular}{cccc} 
Sample & Power density & Substrate & Bsat $(m T)$ \\
\hline YIG powder & - & - & 150 \\
SLM sample A & $95 \mathrm{~kW} / \mathrm{cm}^{2}$ & Non-magnetic - Al & 120 \\
SLM sample B & $150 \mathrm{~kW} / \mathrm{cm}^{2}$ & $\begin{array}{c}\text { Magnetic - YIG } \\
\text { powder }\end{array}$ & 90 \\
SLM sample C & $1 \mathrm{MW} / \mathrm{cm}^{2}$ & $\begin{array}{c}\text { Magnetic - YIG } \\
\text { powder }\end{array}$ & 90
\end{tabular}

Table 1 shows the saturation magnetization calculated for the four samples. Bsat values were determined by dividing the magnetic moment measured using VSM by the sample volume measured with the high precision scale. In the literature, the value of saturation magnetization is $175 \mathrm{mT}$ for bulk YIG. ${ }^{31-32}$ YIG powder was found to be close to this value. Bsat was measured to be $20 \%$ less than YIG powder value in the case of an $\mathrm{Al}$ substrate while it is decreased by $40 \%$ in the case of the YIG powder substrate (samples B and C) independently of the laser power. An explanation may be found in the thermal conductivity of the substrate. Bulk $\mathrm{Al}$ has a high conductivity while YIG powder conductivity should be less than the low bulk YIG conductivity. This behavior could induce a longer heat diffusion enhancing chemical or structural changes. To check this hypothesis, Chemical and structural analyses have to be performed.

\subsection{Raman analysis}

Raman measurements are made to track associated changes in molecular structure. The Raman spectrum of YIG powder is measured with an argon laser at $\lambda=488 \mathrm{~nm}$ and the resolution used was 1800 lines $/ \mathrm{mm}$. Raman spectra of the powder after SLM (Sample A, B and C) are obtained using a helium neon laser at incident wavelength $\lambda=633 \mathrm{~nm}$ with a resolution of 600 lines $/ \mathrm{mm}$. All spectra were recorded in a wide range of wave numbers, between 100 and $1000 \mathrm{~cm}^{-1}$. For severely damaged samples, longer accumulation times were required to increase the signal-to-noise ratio. Fig. 4 shows the evolution of the vibration modes peaks of the non-melted and melted YIG powder by SLM as a function of the laser power, hence as a function of temperature.

The total irreducible representations associated with $\mathrm{YIG}$ vibrations according to the $\mathrm{O}_{\mathrm{h}}-\mathrm{Ia} 3 \mathrm{~d}$ group are given by Mallmann et al. ${ }^{33}$ as follows: $3 \mathrm{~A}_{1 \mathrm{~g}}+5 \mathrm{~A}_{2 \mathrm{~g}}+8 \mathrm{E}_{\mathrm{g}}+14 \mathrm{~F}_{1 \mathrm{~g}}+14 \mathrm{~F}_{2 \mathrm{~g}}+5 \mathrm{~A}_{1 \mathrm{u}}+5 \mathrm{~A}_{2 \mathrm{u}}+10 \mathrm{E}_{\mathrm{u}}+18 \mathrm{~F}_{1 \mathrm{u}}+16 \mathrm{~F}_{2 \mathrm{u}}$. The total of these modes is equal to 98 , distributed in 55 silent modes $\left(5 \mathrm{~A}_{1 \mathrm{u}}+5 \mathrm{~A}_{2 \mathrm{~g}}+5 \mathrm{~A}_{2 \mathrm{u}}+10 \mathrm{E}_{\mathrm{u}}+14 \mathrm{~F}_{1 \mathrm{~g}}+16 \mathrm{~F}_{2 \mathrm{u}}\right), 1$ acoustic mode $\left(1 \mathrm{~F}_{1 \mathrm{u}}\right), 25$ active Raman modes $\left(3 \mathrm{~A}_{1 \mathrm{~g}}+8 \mathrm{E}_{\mathrm{g}}+14 \mathrm{~F}_{2 \mathrm{~g}}\right)$ and 17 infrared modes $\left(17 \mathrm{~F}_{1 \mathrm{u}}\right)$. The vibration modes of $3 \mathrm{~A}_{1 \mathrm{~g}}, 8 \mathrm{E}_{\mathrm{g}}$, $14 \mathrm{~F}_{2 \mathrm{~g}}$ and $17 \mathrm{~F}_{1 \mathrm{u}}$ of $\mathrm{YIG}$ are respectively given by $\left(v_{1}, v_{2}, \mathrm{~L}\right),\left(v_{1}, 2 v_{2}, v_{3}, v_{4}, \mathrm{~L}, \mathrm{~T}, \mathrm{~T}_{1}\right),\left(v_{2}, 3 v_{3}, 3 v_{4}, 2 \mathrm{~L}, 3 \mathrm{~T}, 2 \mathrm{~T}_{2}\right)$ and $\left(v_{2}\right.$, $3 v_{3}, 3 v_{4}, 2 \mathrm{~L}, 3 \mathrm{~T}, 2 \mathrm{~T}_{1}, 3 \mathrm{~T}_{2}$ ), where $\mathrm{T}, \mathrm{T}_{1}$ and $\mathrm{T}_{2}$ represent the translation of $\left[\mathrm{FeO}_{4}\right]^{5-}$ (tetrahedral sites), $\mathrm{Fe}^{3+}$ (octahedral sites) and $\mathrm{Y}^{3+}$ respectively. The rotational degree of freedom $(\mathrm{R})$ of the free molecule becomes vibrating lattice modes $(\mathrm{L})$ in the crystal. 
Table 2 describes the assignments of all Raman modes that are observed in the spectrum in Fig. 4 corresponding to the polycrystalline YIG powder, where the spectrum has the same general characteristics as reported in literature. ${ }^{33-35}$ Only 11 of the 25 active Raman modes expected were observed. These modes can identify the molecules presented in the sample.

Table 2. Vibration modes of the peaks in the Raman spectra of unmelted YIG powder.

\begin{tabular}{|ccc|}
\hline Wave numbers $\left(\mathbf{c m}^{-1}\right)$ & Wave numbers in the ref. [1] & Assignment \\
\hline $\mathbf{1 2 7 . 3}$ & 130 & $\mathrm{~T}+\mathrm{T}_{1}+\mathrm{T}_{2}$ \\
$\mathbf{1 7 0}$ & 172 & $\mathrm{~T}+\mathrm{T}_{1}+\mathrm{T}_{2}$ \\
$\mathbf{1 9 0 . 8}$ & 192 & $\mathrm{~T}+\mathrm{T}_{1}+\mathrm{T}_{2}$ \\
$\mathbf{2 3 4 . 2}$ & 237 & $\mathrm{~L}\left[\mathrm{FeO}_{4}\right]^{5-}$ \\
$\mathbf{2 7 0 . 9}$ & 272 & $\mathrm{~L}\left[\mathrm{FeO}_{4}\right]^{5-}$ \\
$\mathbf{3 3 9 . 6}$ & 342 & $v_{4}\left(\mathrm{~F}_{2 \mathrm{~g}}\right)$ \\
$\mathbf{3 7 3 . 6}$ & 376 & $v_{4}\left(\mathrm{~F}_{2 \mathrm{~g}}\right)$ \\
$\mathbf{4 1 3 . 9}$ & 418 & $v_{2}\left(\mathrm{E}_{\mathrm{g}}\right)$ \\
$\mathbf{4 4 4 . 5}$ & 445 & $v_{2}\left(\mathrm{Eg}_{\mathrm{g}}\right)$ \\
$\mathbf{5 0 4 . 3}$ & 504 & $v_{3}\left(\mathrm{~A}_{1 \mathrm{~g}}\right)$ \\
$\mathbf{5 8 6 . 3}$ & 587 & $\mathrm{v}_{3}\left(\mathrm{~F}_{2 \mathrm{~g}}\right)$ \\
\hline
\end{tabular}

These results make it possible to distinguish two collections of modes: two between 300 and $500 \mathrm{~cm}^{-1}$, and two between 500 and $750 \mathrm{~cm}^{-1}$. All these modes are associated with internal vibrations of the $\mathrm{FeO}_{4}$ molecular group, while modes below $300 \mathrm{~cm}^{-1}$ have been classified as translations $(\mathrm{T})$ of $\mathrm{Y}^{3+},\left[\mathrm{FeO}_{4}\right]^{5-}$ and/or $\left[\mathrm{FeO}_{6}\right]^{9-}$. The sequence of internal vibration modes observed above $300 \mathrm{~cm}^{-1}$ was $v_{4}<v_{2}<v_{3}$.

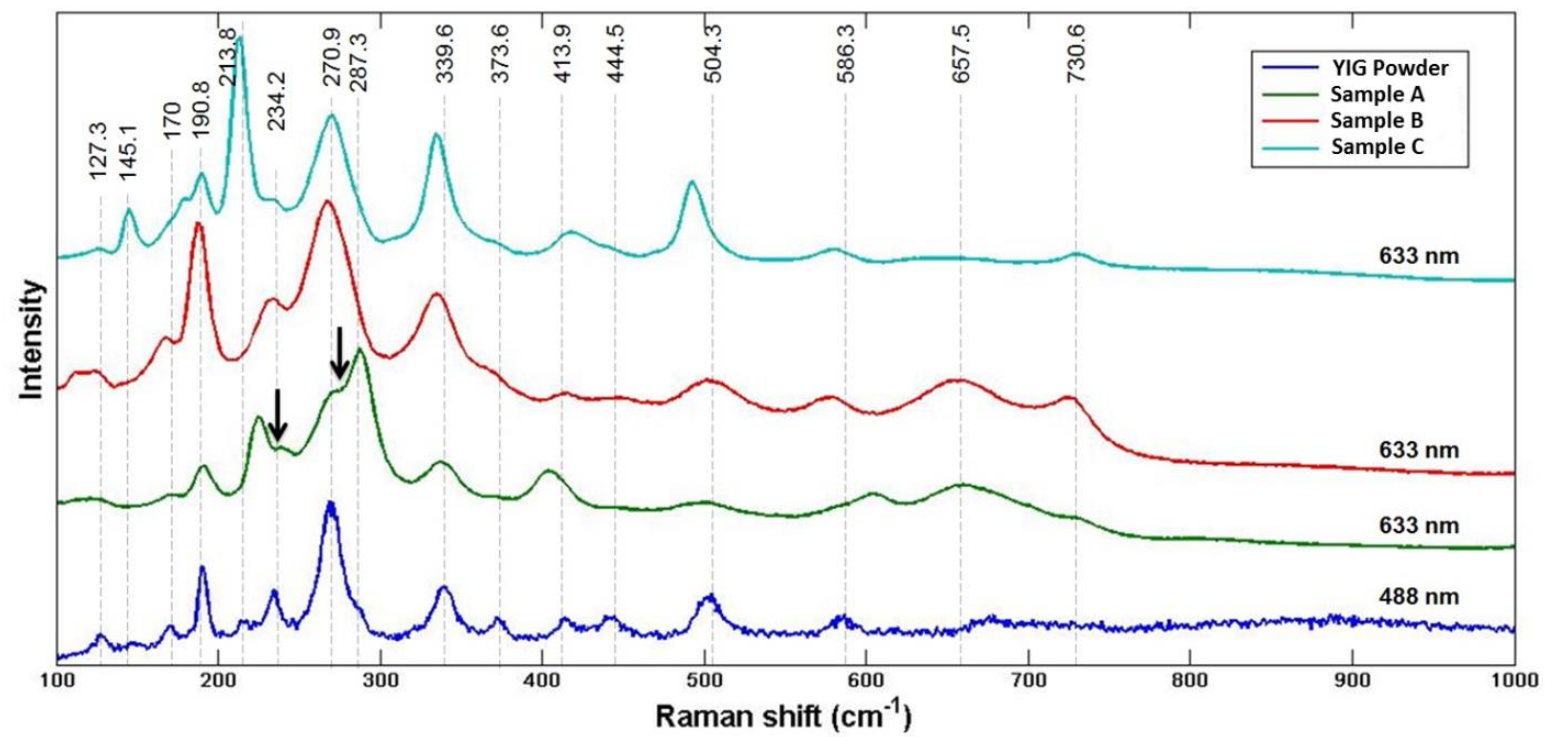

Figure 4: Raman spectra of YIG powder and SLM samples.

The figure shows the spectra measured after laser melting with different powers in comparison with that of the powder. The spectrum of sample A fused at a low power of $0.6 \mathrm{~W}$ shows a significant variation from that of the powder, where a decrease in the intensity of some YIG peaks is clearly visible. In addition, the appearance of two doublets of the internal vibration modes (marked by arrows in the figure) can be distinguished. This is caused by a coupling of the vibrations of two coplanar molecules in the elementary crystal lattice. The first doublet has peaks which are at wave numbers of 224.2 and $234.2 \mathrm{~cm}^{-1}$ associated with the modes: $\mathrm{A}_{1 \mathrm{~g}}$ of $\mathrm{Fe}_{2} \mathrm{O}_{3}$ and $\mathrm{L}\left[\mathrm{FeO}_{4}\right]^{5-}$ of $\mathrm{YIG}$, respectively. For the second one, the peaks are located on 270.9 and $287.3 \mathrm{~cm}^{-1}$ and associated to modes: $\mathrm{L}\left[\mathrm{FeO}_{4}\right]^{5-}$ of $\mathrm{YIG}$ and $\mathrm{E}_{\mathrm{g}}$ of $\mathrm{Fe}_{2} \mathrm{O}_{3}$, respectively. Thus, low energy fusion causes a phase transition (the appearance of the hematite phase of the molecule $\mathrm{Fe}_{2} \mathrm{O}_{3}$ ) by heat 
treatment while keeping the garnet phase of the sample in a minimal amount. This confirms that this is the lowest peak intensity of this phase.

The Raman spectra of samples B and C present a modification of the intensity and a shift of certain peaks, compared to that of YIG powder. New peaks corresponding to the orthoferrite $\mathrm{YFeO}_{3}$ were found, ${ }^{36}$ including the peak at $657.5 \mathrm{~cm}^{-1}$ for sample $\mathrm{B}$, and others corresponding to the magnetite phase molecule $\mathrm{Fe}_{3} \mathrm{O}_{4}$ are located at 145.1 and $213.8 \mathrm{~cm}^{-1}$ for sample C.

The appearance of these new phases is probably due to the recrystallization of the material structure caused by heating. Thus, due to equilibrium, an amount of $\mathrm{YFeO}_{3}$ and $\mathrm{Fe}_{2} \mathrm{O}_{3}$ can be observed in the YIG.

$$
\mathrm{Y}_{3} \mathrm{Fe}_{5} \mathrm{O}_{12} \longleftrightarrow 3 \mathrm{YFe}_{3}+\mathrm{Fe}_{2} \mathrm{O}_{3}
$$

In conclusion, in each spectrum there are indeed two phases. The first phase is the garnet phase of YIG. The second is a new phase that depends on the temperature governed by the laser power. We notice the appearance of the hematite at low laser power (low temperature) and the magnetite at higher laser power (higher temperature).

\section{CONCLUSION}

To conclude, the feasibility of using selective laser melting to perform additive manufacturing of YIG ferrite powder, a soft magnetic material, was demonstrated. The fabricated layers were magnetically characterized using VSM. They always exhibit a hysteresis loop, which characterize a magnetic behavior, independently of the magnetic nature of the substrate. The nature of the substrate seems to modify the saturation magnetization. This was attributed to the thermal conductivity of the substrate. Finally, Raman analysis shows that part of the YIG was decomposed in a weak magnetic phase of iron oxide III depending on temperature. For the highest temperature, magnetite signature was found in Raman spectra of the fabricated layer while hematite was found for a lower temperature close to YIG melting.

\section{ACKNOWLEDGEMENTS}

This work was supported by the University Jean Monnet Foundation.

This work has benefited from public aid administered by the French National Research Agency (ANR) under the Programme Investissement d'Avenir (PIA), which has the reference ANR-17-EURE-0026.

The authors acknowledge Didier Dufeu (Institut Néel, CNRS/UGA UPR 2940, Grenoble) for the technical support in making the VSM available.

The authors acknowledge Telecom Saint-Etienne engineering school for giving access to their laser marking equipment.

\section{REFERENCES}

[1] Lopez-Villegas, J. M., Vidal, N. and Del Alamo, J. A., "Toroidal versus spiral inductors in multilayered technologies," IEEE Radio Frequency Integrated Circuits Symposium, 55-58 (2016).

[2] Yang, S., Roy, L., Bray, J. R. and Vincent, D., "Modeling and simulation of a partially-magnetized ferrite ltcc circulator," IEEE-MTT-Numerical Electromagnetic and Multiphysics Modeling and Optimization, 1-4 (2015).

[3] Xie, Y., Ye, S., Reyes, C., Sithikong, P., Popa, B. I., Wiley, B. J. and Cummer, S. A., "Microwave metamaterials made by fused deposition 3D printing of a highly conductive copper-based filament," App. Phys. Letters 110, 181903_1-5 (2017).

[4] Yamamoto, Y., Makino, A., Yamaguchi, T. and Sasada, I., "Fine grained ferrite for low profile transformer," IEEE Trans. on Magnetics 33(5), 3742-3744 (1997).

[5] Yan, Y., Ding, C., Ngo, K. D. T., Mei, Y. and Lu, G. Q., "Additive manufacturing of planar inductor for power electronics applications," Proc. of Intern. Symposium on 3D Power Electron. Integration and Manufacturing, 116 (2016). 
[6] Mariotti, C., Alimenti, F., Roselli, L. and Tentzeris, M. M., "High performance RF devices and components on flexible cellulose substrate by vertically integrated additive manufacturing technologies," IEEE Trans. On Microwave Theory and Techniques 65(1), 62-71 (2017).

[7] Liang, W., Raymond, L. and Rivas, J., "3D printed air core inductors for high frequency power converters," IEEE Trans. on Power Electronics 31(1), 52-64 (2016).

[8] Vaed, K., Florkey, J., Akbar, S. A., Madou, M. J., Lannutti, J. J. and Cahill, S. S., "An additive micromolding approach for the development of micromachined ceramic substrates for RF applications," Journal of Microelectromechanical Systems 13(3), 514-525 (2004).

[9] Liang, M., Shemelya, C., MacDonald, E., Wicker, R. and Xin, H., "3-D Printed Microwave Patch Antenna via Fused Deposition Method and Ultrasonic Wire Mesh Embedding Technique," IEEE Antennas and Wireless Propagation Letters 14, 1346-1349 (2015).

[10] Xin, H. and Liang, M., "3-D-Printed Microwave and THz Devices Using Polymer Jetting Techniques," IEEE Proc. 105(4), 737-755 (2017).

[11] Yan, Y., Ngo, K. D. T., Mei, Y. and Lu, G. Q.., "Additive manufacturing of magnetic components for power electronics integration," Proc. Of Intern. Conf. on Electron. Packaging, 368-371 (2016).

[12] Yan, Y., Liu, L., Ding, C., Nguyen, L., Moss, J, Mei, Y. and Lu, G. Q., "Additive manufacturing of magnetic components for heterogeneous integration," Proc. of IEEE Electron. Components and Technol. Conf., 324-330 (2017).

[13] Wang, Y., Castles, F. and Grant, P. S., "3D Printing of NiZn ferrite/ABS Magnetic Composites for Electromagnetic Devices," MRS Proc. 1788, 29-35 (2015).

[14] White, E. M. H., Kassen, A. G., Simsek, E., Tang, W., Ott, T. T. and Anderson, I.E., "Net shape processing of Alnico magnets by additive manufacturing," IEEE Trans. Magn. 53, art. 2101606 (2017).

[15] Zhang, B., Fenineche, N. E., Zhu, L., Liao, H. and Coddet, C., "Studies of magnetic properties of permalloy (Fe-30\% Ni) prepared by SLM technology," J. Magn. Magn. Mater. 324, 495-500 (2012).

[16] Mikler, C. V., Chaudhary, V., Soni, V., Gwalani, B., Ramanujan, R. V. and Banerjee, R., "Tuning the phase stability and magnetic properties of laser additively processed Fe-30at\% Ni soft magnetic alloys," Mater. Lett. 199, 88-92 (2017).

[17] Mikler, C. V., Chaudhary, V., Borkar, T., Soni, V., Jaeger, D., Chen, X., Contieri, R., Ramanujan, R. V. and Banerjee, R., "Laser Additive Manufacturing of Magnetic Materials," JOM 69, 532-543 (2017).

[18] Kustas, A. B., Susan, D. F., Johnson, K., Whetten S. R., Rodriguez, M. A., Dagel, D. J., Michael, J. R., Keicher, D. and Argibay, N., "Characterization of the Fe-Co- $1.5 \mathrm{~V}$ soft magnetic alloy processed by laser engineered net shaping (LENS)," Addit. Manuf. 21, 41-52 (2018).

[19] Garibaldi, M., Ashcroft, I., Hillier, N., Harmon, S. A. C. and Hague, R., "Relationship between laser energy input, microstructures and magnetic properties of selective laser melted Fe-6.9\%wt Si soft magnets," Mater. Charact. 143, 144-151 (2018).

[20] Moore, J. D., Klemm, D., Lindackers, D., Grasemann, S., Träger, R., Eckert, J., Löber, L., Scudino, S., Katter, M., Barcza, A., Skokov, K. P. and Gutfleisch, O., "Selective laser melting of $\mathrm{La}(\mathrm{Fe}, \mathrm{Co}, \mathrm{Si}) 13$ geometries for magnetic refrigeration," J. Appl. Phys. 114, Art. 043907 (2013).

[21] Kruth, J. P., Mercelis, P., Van Vaerenbergh, J., Froyen, L. and Rombouts, M., "Binding mechanisms in selective laser sintering and selective laser melting", Rapid Prototyping Journal 11(1), 26-36 (2005).

[22] Vilar, R. M., "Laser cladding," Proc. SPIE 5147, 385-392 (2003).

[23] Griffith, M. L., Ensz, M. T., Puskar, J. D., Robino, C. V., Brooks, J. A., Philliber, J. A., Smugeresky, J. E. and Hofmeister, W. H., "Understanding the Microstructure and Properties of Components Fabricated by Laser Engineered Net Shaping (LENS), " MRS Proc. 625, p. 9-20 (2000).

[24] Yap, C.Y., Chua, C.K., Dong, Z.L., Liu, Z.H., Zhang, D.Q., Loh, L.E. and Sing, S.L., "Review of selective laser melting: materials and applications," App. Phys. Rev. 2, 041101_1-21 (2015).

[25] Yadroitsev, I. and Smurov, I., "Selective laser melting technology: from the single laser melted track stability to 3D parts of complex shape," Phys. Proc. 5(B), 551-560 (2010).

[26] Hanzl, P., Zetek, M, Bakša, T. and Kroupa, T., "The Influence of Processing Parameters on the Mechanical Properties of SLM Parts," Procedia Engineering 100, 1405-1413 (2015).

[27] Carter, L. N., Martin, C., Withers, P. J. and Attallah, M. M., "The influence of the laser scan strategy on grain structure and cracking behaviour in SLM powder-bed fabricated nickel superalloy," J. of Alloys and Compounds 615, 338-347 (2014) 
[28] Udroiu, R., "powder bed additive manufacturing systems and its applications," academic journal of manufacturing engineering 10(4), 122-129 (2012).

[29] Boudiar, T., Payet-Gervy, B., Blanc-Mignon, M. F., Rousseau, J. J., Le Berre, M. and Joisten, H., "Magnetooptical properties of yttrium iron garnet (YIG) thin films elaborated by radio frequency sputtering," J. of Magnetism and Magnetic Materials 284, 77-85 (2004).

[30] Ishii, K., Hoshi, Y., Naoe, M. and Yamanaka, S, "Preparation of stoichiometric YIG films by sputtering," Ferrites: Proc. of international conference, Japan, 831-834 (1980).

[31] Enke, K., Fleischhauer, J., Gunßer, W., Hansen, P., Nomura, S., Tolksdorf, W., Winkler, G. and Wolfmeier, U, [Magnetic and other properties of oxides and related compounds - Part A: garnets and perovskites], LandoltBörnstein - Group III condensed matter 12A, Hellwege K M and Hellwege A. M. (Ed.), Springer materials, Berlin, 500-516 (1978).

[32] Ibrahim, N. B., Edwards, C., Palmer, S.B., "Pulsed laser ablation deposition of yttrium iron garnet and ceriumsubstituted YIG films," J. Magn. Magn. Mater 220, 183-194 (2000).

[33] Mallmann, E. J. J., Sombra, A. S. B., Goes, J. C. and Fechine, P. B. A., "Yttrium iron garnet: properties and applications review," in Solid State Phenomena, 2013, vol. 202, p. 65-96.

[34] Schileo, G., Feteira, A., Reaney, I. M., Postolache, P., Mitoseriu, L. and Reichmann, K., "Characterization of Yttrium iron Garnet/Barium Titanate multiferroic composites prepared by sol-gel and coprecipitation methods," International journal of applied ceramic technology 11(3), 457-467 (2014).

[35] White, W. B. and Keramidas, V. G., "Raman spectra of yttrium iron garnet and two vanadium garnets," J. of American Ceramic Soc. 54(9), 472-473 (1971).

[36] De Faria, D. L. A., Venâncio Silva, S. and De Oliveira, M. T., "Raman microspectroscopy of some iron oxides and oxyhydroxides, " J. of Raman spectroscopy 28(11), 873-878 (1997). 